\title{
Preliminary experiments on the effect of methionine sulphoximine on the developing chick and on transplantable tumours
}

\author{
By THE LATE EDWARD MELLANBY \\ Nutrition Building, National Institute for Medical Research, \\ Mill Hill, London, N.W. 7 \\ (Received I May 1956) \\ FOREWORD \\ By May Mellanby
}

It will be recalled that my husband first described the toxic effects of agenized flour on animals in 1946 and was later concerned in the isolation of the toxic agent, methionine sulphoximine (Mellanby, I946; Campbell, Work \& Mellanby, 1951). In experiments with dogs, ferrets, rabbits and rats having in their diet either the treated flour or methionine sulphoximine, he found that degeneration of nerve cells and various pathological conditions of the alimentary tract often developed. His interest in the subject was not only academic; he felt that further work might lead to a better understanding of epilepsy in man and probably other conditions similar to those observed in experimental animals. During the summer of 1954 , according to his usual custom of returning to former studies when his interest was re-stimulated or when new techniques made a fresh approach possible, he decided to investigate the problem from other angles. In the first place, in order to determine the toxic effects of methionine sulphoximine, he began a series of tests on bone growth in tissue culture and planned later to explore its influence on neural and other tissues in vitro. Secondly, he began a comparative investigation of the condition of birds hatched from eggs injected with the sulphoximine or with a control substance, either methionine or saline. He also hoped to test its effect on transplantable tumours in animals, and had, in fact, an hour before he died written to Professor A. Haddow, of the Chester Beatty Research Institute, asking for a Jensen rat sarcoma, which had been used in much of his earlier work on cancer problems.

After my husband's death, those experiments that were in progress in this laboratory were completed. In addition, some preliminary tests on tumours were made on the lines which he had envisaged. For this purpose tumour-bearing rats and mice were obtained through the kindness of Professor Haddow. Later, Professor H. N. Green, of Leeds, also made a few tests with his strain of rats. Although the findings in each section of this work can only be regarded as preliminary, they are given here for various reasons, the chief one being that $I$, and all who have co-operated with me, hope that others may be stimulated to pursue this line of research.

It is difficult to acknowledge the services so willingly given by many in completing 
the experiments after my husband's death and in reporting the results obtained. All the practical work, except some of that on tumours, was done at the Nutrition Building with the very competent help of Mr R. J. C. Stewart, chief technician, assisted by Miss Hilda G. Sheppard and other members of the staff. Dr Honor B. Fell, of the Strangeways Research Laboratory, Cambridge, and Dr Janet S. F. Niven, of the National Institute for Medical Research, took an active interest throughout and also performed the autopsies on the older birds. The results of the experiments were analysed, tabulated and prepared for presentation by Dr W. J. Martin, of the Medical Research Council's Statistical Research Unit. With Dr Niven he was partly responsible for the writing up of the egg experiments. Dr Fell prepared the section on tissue culture and Professor H. N. Green the note on tumours. Mrs Marion Kelley rendered valuable assistance in assembling the various parts of the paper.

EXPERIMENTAL AND RESULTS

\section{Preparation of $\mathrm{L}-$-methionine sulphoximine}

For most of the experiments in which L-methionine sulphoximine was used, it was prepared in the Nutrition Building. It has the formula<smiles>C[Sn]([NH-])([O-])CCCC(N)C(=O)O</smiles>

The method of preparation was based on that of Bentley, McDermott \& Whitehead (1951), but the original procedure of Toennies \& Kolb (1939) for obtaining DLmethionine sulphoxide was followed in preference to the modification introduced by the first-named authors. In a few of the preliminary experiments, however, material kindly provided by Dr Reiner of Wallace and Tiernan Products Inc., Belleville, N.J., U.S.A., and by $\mathrm{Dr}$ T. Moran of the Research Association of British Flour-Millers, St Albans, was employed. The DL-methionine sulphoximine used was supplied by Imperial Chemical Industries Ltd.

\section{Tissue-culture experiments}

The value of tissue-culture methods for the study of the direct action of substances of biological interest was strikingly demonstrated by the work of Fell \& Mellanby (1950, 1952) on the effect of hypervitaminosis A on foetal bones cultivated in vitro, and similar techniques were used to observe the action of vitamin A on embryonic epidermis (Fell \& Mellanby, 1953) and of thyroxine on developing bone rudiments in vitro (Fell \& Mellanby, I955). Tissue culture thus provides a method of choice for the investigation of the direct cellular effects of methionine sulphoximine, and the following experiments were made in connexion with the problem.

\section{Procedure}

The cartilaginous rudiments of the femur, tibia, humerus, radius, fibula and ulna of 6-day chick embryos of the same breed were grown by the watch-glass method (Fell \& Robison, 1929; Fell \& Mellanby, 1952). The culture medium consisted of three parts 
of cock plasma mixed with one part of chick-embryo extract which formed a semisolid clot; the extract was made from $\mathbf{1} 3$-day embryos with Tyrode solution containing I $\%$ glucose. The rudiments were transplanted to fresh medium every 2 days. One of each pair of bones was explanted in medium to which either L- or DL-methionine sulphoximine dissolved in isotonic saline had been added, usually to give a concentration of $5 \mathrm{mg} / \mathrm{l}$. culture medium; the other rudiment was grown in control medium containing either the same quantity of isotonic saline as was present in the experimental clots or the same amount of a solution of methionine in saline, its concentration being equal to that of methionine sulphoximine in the corresponding experimental cultures. In all, ro3 pairs of bones were used. The length of the rudiments was measured by means of a micrometer eye-piece at 2-day intervals.

\section{Results}

Treatment with methionine sulphoximine retarded the growth of 89 of the 103 bones. Examples are shown in Fig. I. Of the remaining fourteen, eleven appeared to be stimulated when grown in this medium and three grew at a rate similar to that of their

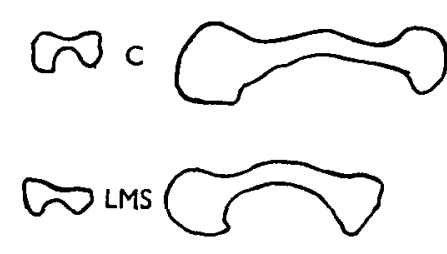

Humerus
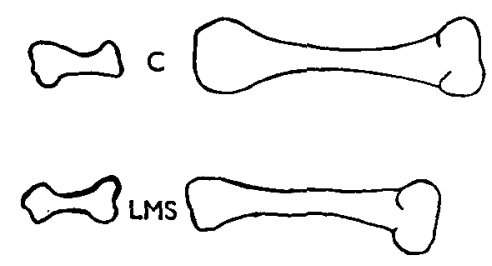

Femur

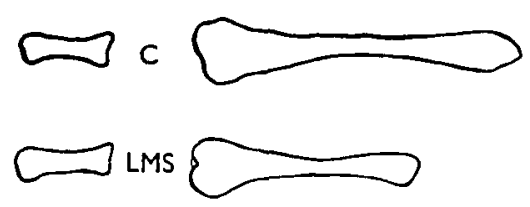

Tibia

Fig. 1. Camera lucida drawings of living humeri, femora and tibiae from 6-day chick embryos, at explantation and after 8 days' cultivation, showing inhibition of growth in the explants treated with $5 \mathrm{mg} / \mathrm{l}$. culture medium of L-methionine sulphoximine (LMS). C, control bones; LMS, experimental bones.

controls. Nine of these 'exceptions' were radii and ulnae, which often appear to react differently from other bones to external influences (Fell \& Mellanby, 1955); the other five included three humeri and one femur, which had lower concentrations of methionine sulphoximine than were generally used, and one tibia. The different effect of methionine sulphoximine on the various rudiments is well shown by the average growth curves reproduced in Fig. 2. It is seen that the inhibition of growth was greatest in the femur, tibia and humerus, and least in the radius and ulna. (The fibula results are omitted from the graphs as there were only four pairs in all.) In the same concentration, L-methionine sulphoximine was more growth-inhibitory than DLmethionine sulphoximine (Fig. 3). 
Vol. 10

As it seemed possible that the form in which the sulphur was present in the test substance might be responsible for some of the effects of methionine sulphoximine, a few experiments were made in which sulphur as sulphite, sulphide or sulphate was tested against the saline control. In all experiments the bones grew equally well.

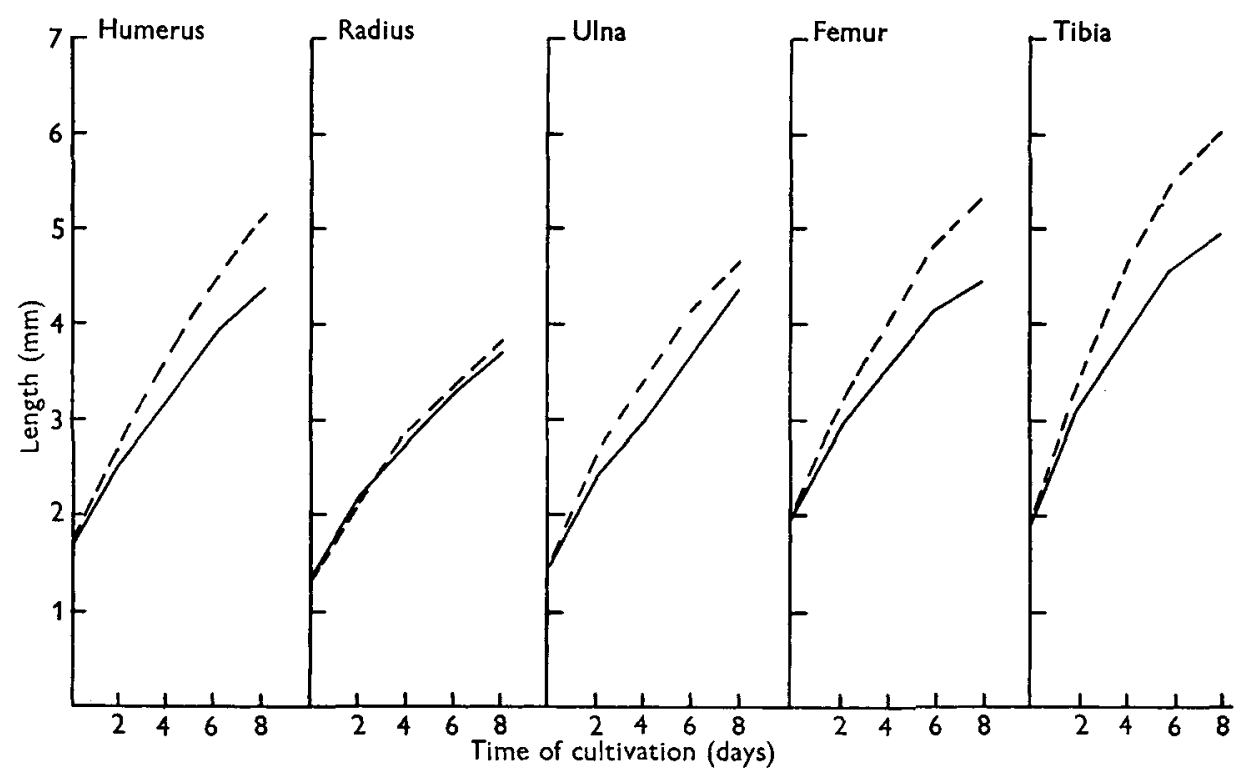

Fig. 2. Mean growth curves showing the effect of $\mathrm{L}$-methionine sulphoximine $(5 \mathrm{mg} / \mathrm{l}$.) on the growth rate of explanted limb-bone rudiments of chick embryos. - - - , control bones; - , experimental bones. The femur, tibia and humerus are more severely affected than the radius and uina.

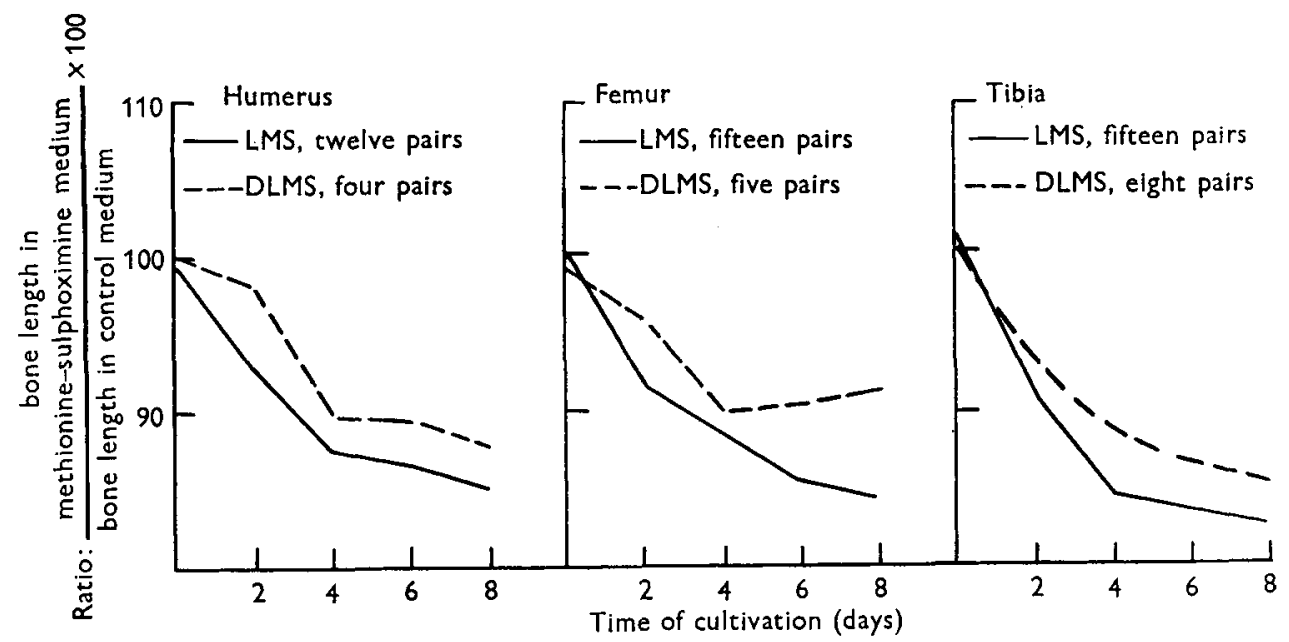

Fig. 3. Mean growth curves of explanted femora, tibiae and humeri of chick embryos, showing that L-methionine sulphoximine (LMS) inhibits growth more than DL-methionine sulphoximine (DLMS). 


\section{Effect of injections of methionine sulphoximine into eggs}

The work described in this section is an investigation into the condition of Light Sussex chicks hatched from eggs injected with L- or DL-methionine sulphoximine compared with that of control birds from eggs injected with L- or DL-methionine or saline. Some chicks died or were killed at an early age; others were kept until sexual maturity was reached and the two groups were compared before and after death.

\section{Procedure}

Various preliminary trials were made to discover the most suitable age at which to inject the eggs and the amount of the test substance likely to give the most satisfactory results. Eventually $0.2 \mathrm{mg}$ methionine sulphoximine dissolved in $0.05 \mathrm{ml}$. isotonic saline was injected on the $4^{\text {th }}$ day of incubation, before the vascular system was too far developed, so avoiding trauma during injection.

On the $4^{\text {th }}$ day of incubation the egg was kept for a few minutes with its larger end uppermost, so that the embryo would settle on top, and was then examined against an egg-testing lamp. The lower right quadrant was cleaned with ethanol and a small hole drilled through the shell with a foot-controlled dental drill having a no. 3 rose-head burr, care being taken not to penetrate the membrane. After the shell dust had been removed, the solution was injected into the yolk sac with a tuberculin syringe and a $I_{2} \frac{1}{2}$ in. no. 20 hypodermic needle. The hole in the shell was again cleaned and sealed with paraffin wax (melting point $60^{\circ}$ ). No further treatment was given and incubation was allowed to continue for the normal period.

\section{Results}

Hatchings. In the main series of experiments, over a period of 6 months, 189 eggs were injected. Of these 155 were fertile, but only 67 hatched. Details were as follows:

$\begin{array}{lcccc}\text { Substance injected } & \begin{array}{c}\text { No. of } \\ \text { eggs }\end{array} & \begin{array}{c}\text { No. } \\ \text { fertile }\end{array} & \begin{array}{c}\text { No. } \\ \text { hatched }\end{array} & \begin{array}{c}\text { Percentage of } \\ \text { fertile eggs } \\ \text { hatched }\end{array} \\ \text { Control (methionine or saline) } & 57 & 46 & 31 & 67.4 \\ \text { L-Methionine sulphoximine } & 73 & 60 & \text { 2I } & 35.0 \\ \text { DL-Methionine sulphoximine } & 59 & 49 & \text { I } 5 & 30.6 \\ \text { Total for sulphoximine groups } & \text { I32 } & \text { I09 } & 36 & 33.0\end{array}$

Thus, one injection of $0.2 \mathrm{mg}$ of either sulphoximine compound on the $4^{\text {th }}$ day of incubation reduced the chance of a fertile egg's hatching by one-half. The percentage difference between the two groups was $34 \cdot 4 \pm 8 \cdot 7$, which is significant, i.e. greater than would be expected from chance fluctuations. As the number of birds in each group was small, and the L- and DL-methionine sulphoximine had apparently similar effects on the rate of hatching, it was decided not to differentiate between them at later stages. These birds therefore appear in succeeding tables as the methionine-sulphoximine group. 
Early mortality. During the first 6 weeks after hatching, the mortality rate was high, but higher among the sulphoximine group than among the controls:

\begin{tabular}{|c|c|c|c|}
\hline \multirow[b]{2}{*}{ Substance injected } & \multirow{2}{*}{$\begin{array}{l}\text { Total no. } \\
\text { of birds* }\end{array}$} & \multicolumn{2}{|c|}{$\begin{array}{l}\text { Birds that died in the } \\
\text { first } 6 \text { weeks of life }\end{array}$} \\
\hline & & No. & Percentage \\
\hline Control (methionine or saline) & 26 & 8 & $30 \cdot 8$ \\
\hline Methionine sulphoximine & 35 & 19 & $54 \cdot 3$ \\
\hline
\end{tabular}

The percentage difference between the two groups, $23 \cdot 5 \pm 12 \cdot 9$, just failed to reach a significant level.

Appearance and behaviour of birds. The chicks from the eggs treated with methionine sulphoximine were smaller than the controls; their beaks, limbs and digits were relatively short; their down feathers, which had an oily appearance, were poorly developed, less fluffy and more sparse, which gave them a bald look and accentuated their smaller appearance (Pl. I). In the sulphoximine group there was some delay in the development of the true feathers, which at one stage appeared to have squared, fringed ends. A similar fringe also occurred in the controls, but never to the same extent, and their feathers were of normal shape. Transverse feather markings appeared in both groups, but were much less evident in the controls. Although the two groups were reared under identical conditions and were brought up entirely on the same diet, a baby chick mash and chicken battery pellets (British Oil and Cake Mills) with no greens or any other addition, the difference in the beaks and legs remained throughout life. On the whole the behaviour of all the birds, when young, was similar, although there was a tendency on the part of the treated group to collect more food and debris on their feet and beaks.

The males of the sulphoximine group, on reaching sexual maturity, became more aggressive than their control counterparts. Of the twenty-three older birds that came to autopsy only four males had appropriate controls of the same sex and age that could be used for valid comparison of gonadal development. All four experimental birds showed marked development of the wattles and comb (Pl. 2, I), and their beaks, legs and digits were shorter and relatively thicker than those of the controls. Amongst the females, four pairs were also available for study and, of these, two experimental birds showed combs slightly larger than those of the controls, one pair was identical in this respect, and in the fourth pair comb development was greater in the control. The beak and limb abnormalities observed in the male experimental birds were present also in the female series.

Growth of bones. To gain some idea as to the relative sizes of the birds, the limb bones were measured at death. In the following figures, representing means for fourteen pairs of birds, the lengths of the various bones of the sulphoximine group are expressed as percentages of the lengths of the control bones: humerus 86 , ulna 85 , radius 84 , femur $8 \mathrm{r}$, tibia $8 \mathrm{r}$. It is thus seen that all these bones were shorter in the test than in the control group. 
The tibiae of the birds were also measured at intervals during life by means of X-ray photographs. The periods between successive photographs unfortunately varied up to 3 weeks. Comparisons were not easy, since, although all the birds were X-rayed on the same day, they were of different ages owing to different dates of hatching. Subdivision by sex into the control and test groups resulted on many occasions in only one or two observations at a particular age. Owing to the natural variation in the size of the birds, a growth curve based on the age when measured was very oscillating. The growth curve was therefore averaged by fitting a straight line by the method of least squares to all measurements from ages $I$ to 100 days, the period of most rapid growth. The regression lines found were:

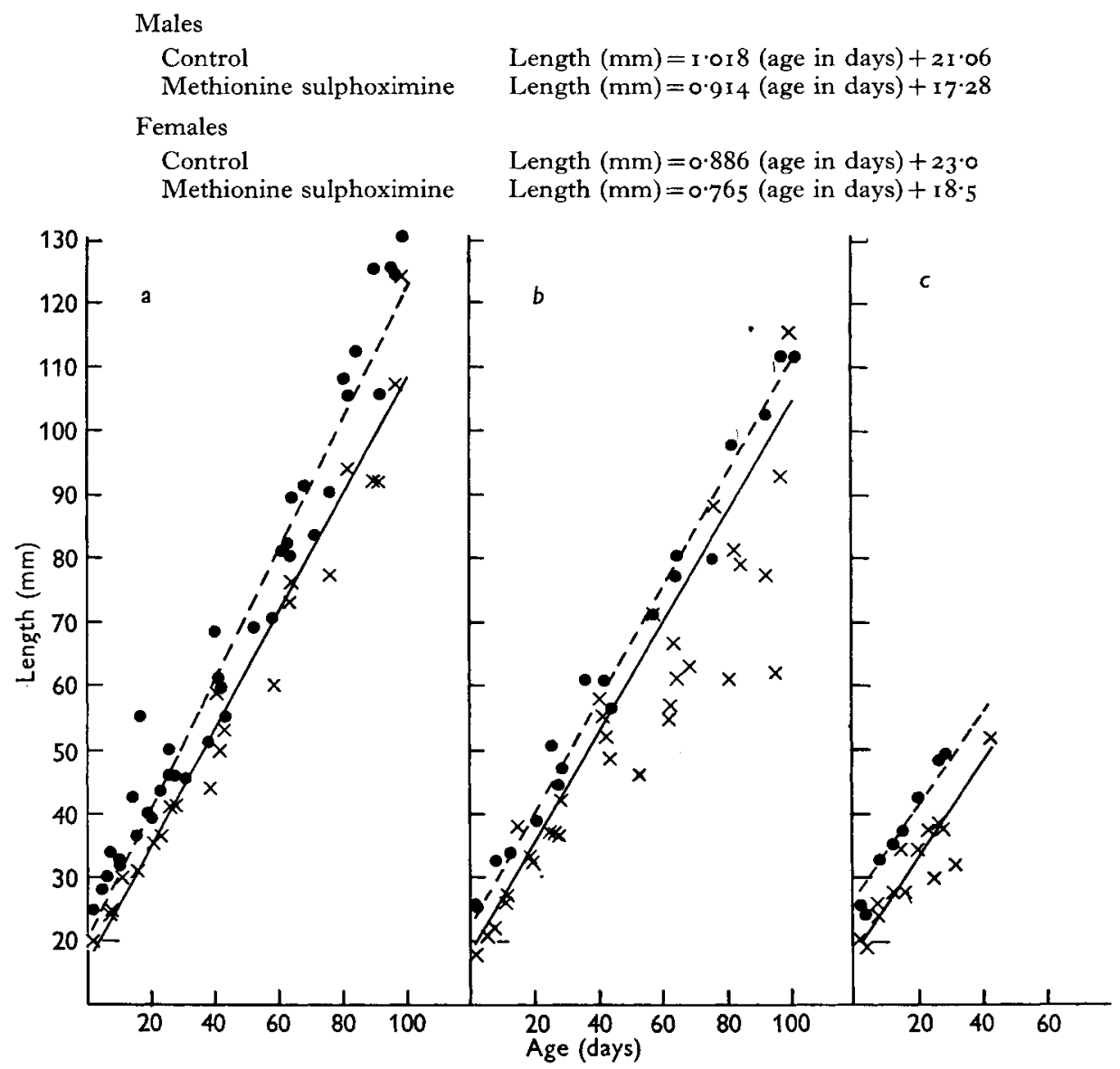

Fig. 4. Growth of tibiae after hatching of chicks from normal eggs and from eggs injected with methionine sulphoximine. (a) males, (b) females, $(c)$ birds not sexed during the experiment. $\bullet$, observations on which broken regression line (control chicks) is based; $x$, observations on which unbroken line (experimental chicks) is based.

These lines, and the actual observations on which they are based, are shown in Fig. $4 a, b$. In both sexes the sulphoximine group had a smaller initial length of tibia, no doubt owing to the action of the sulphoximine on the egg, and the rate of growth after hatching was slightly slower. 
The mean length of tibia for birds aged roo-16o days was:

$\begin{array}{lccc}\text { Males } & \begin{array}{c}\text { No. of } \\ \text { measurements }\end{array} & \begin{array}{c}\text { Mean length of tibia } \\ (\mathrm{mm})\end{array} \\ \text { Control } & 12 & 141.8 & 123.0 \\ \text { Methionine sulphoximine } & 6 & 18.8 \quad P<0.01 \\ \text { Difference } & & & \\ \text { Females } & & & 126.0 \\ \text { Control } & 7 & 109.6 \quad & \\ \text { Methionine sulphoximine } & 14 & 16.4 \quad P<0.01\end{array}$

As is seen from these figures, the sulphoximine group had shorter tibiae. The difference between the two groups was significant for both males and females.

Seventeen birds of the sulphoximine group and sixteen of the controls died and were discarded without their sex being determined. The regression lines for these birds were:

$$
\begin{array}{ll}
\text { Control } & \text { Length }(\mathrm{mm})=0.732 \text { (age in days) }+27 \cdot 16 \\
\text { Methionine sulphoximine } & \text { Length }(\mathrm{mm})=0.759 \text { (age in days) }+18.65
\end{array}
$$

These lines and the observations on which they were based are shown in Fig. $4 c$. Again, as with the separate sexes, the sulphoximine group had shorter tibiae than the controls, but here the rate of growth was the same for both groups.

Since in the main series of experiments the interpretation of the rate of growth of the tibiae from X-ray examination was difficult, owing to the fact that the birds were not all examined at the same ages, another short test was made, in which X-ray photographs were taken at weekly intervals. As it was obvious from the earlier experiments that the proportion of chicks likely to die in the shell or soon after hatching was much greater in the sulphoximine than in the control group, of forty eggs used for this later test twenty-eight were injected with L-methionine sulphoximine and twelve with L-methionine. From twenty-six fertile eggs in the first group, ten chicks $(38.5 \%)$ hatched, and from eleven fertile in the second group seven chicks $(63.6 \%)$ hatched, proportions very similar to those in the main series. Four of the sulphoximine group and one of the controls died within the first Io days after hatching, leaving six in each group. These were kept under identical conditions and fed on the same diet for 6 weeks, when they were all killed. The findings as regards appearance, size of birds and development of feathers were similar to those in the main experiment. Fig. 5 shows the average growth curves for the tibiae of the two groups; the results confirm those illustrated in Fig. $4 c$.

Weight of birds. The distribution of the weight at death or at the end of the experi-

\begin{tabular}{|c|c|c|c|c|}
\hline \multirow[b]{2}{*}{ Age in days } & \multicolumn{2}{|c|}{ Control birds } & \multicolumn{2}{|c|}{$\begin{array}{l}\text { Methionine- } \\
\text { sulphoximine birds }\end{array}$} \\
\hline & No. & $\begin{array}{c}\text { Mean weight } \\
\text { (g) }\end{array}$ & No. & $\begin{array}{c}\text { Mean weight } \\
\text { (g) }\end{array}$ \\
\hline $95-98$ & 3 & I I 40 & 3 & 767 \\
\hline I I I & $I$ & 1520 & & \\
\hline 127 & $\mathbf{I}$ & 2200 & I & 2280 \\
\hline $147-153$ & 7 & 2210 & 5 & 2068 \\
\hline 172 & $I$ & 2680 & I & I 880 \\
\hline 215 & & & 4 & 2355 \\
\hline
\end{tabular}
ment for birds surviving over 90 days was as follows: 
Although the number of birds in each age group was too small for any definite conclusions to be drawn, there was a suggestion that the sulphoximine group were lighter than the controls.

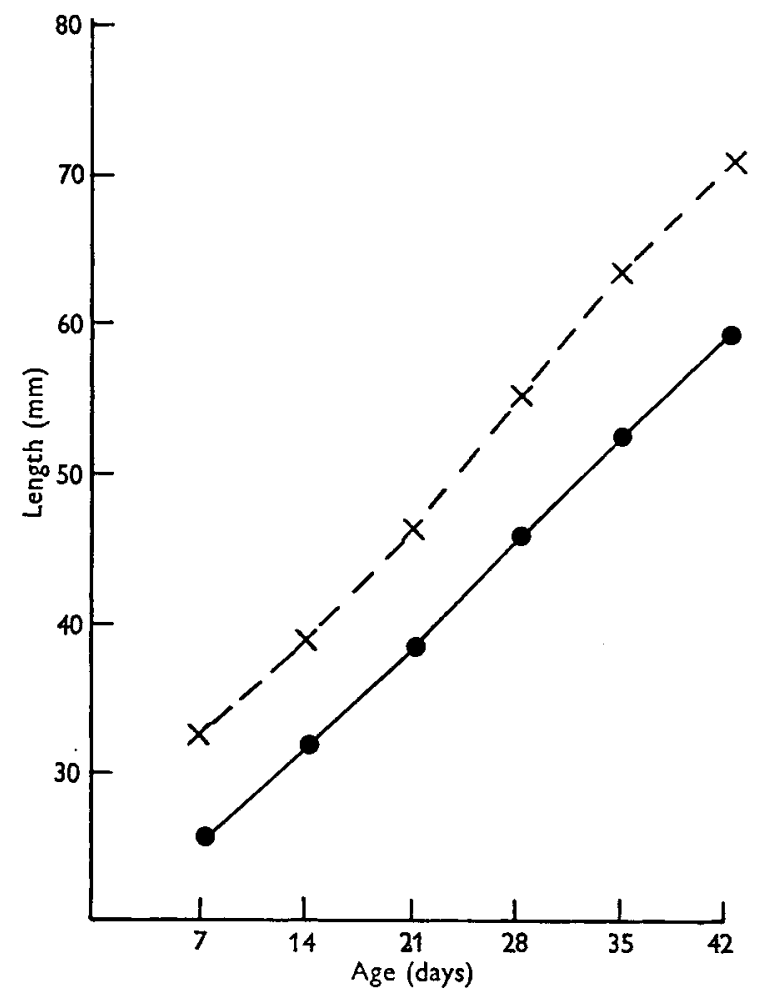

Fig. 5. Growth curves of tibiae of control chicks from eggs injected with L-methionine and of experimental chicks from eggs injected with L-methionine sulphoximine, plotted from $\mathrm{X}$-ray photographs taken at the same ages. Mean values for groups of six birds. - - , control chicks; - - , experimental chicks.

Post-mortem findings. In the females at autopsy no consistent differences were found in the degree of gonadal development or in any of the other organs or tissues examined, including the ductless glands. In the male series the only differences observed were in the testes, which were much larger in the experimental than in the control birds $(\mathrm{Pl} .2,2)$. Histologically, in two birds aged 22 weeks which, on the $4^{\text {th }}$ day of incubation, had been injected with L-methionine sulphoximine and saline respectively, active spermiogenesis with abundant spermatozoa in the seminiferous tubules was present in the former, whereas in the control the stage of development was that of spermatocytogenesis only, without spermatozoa (P1. 2, 3). In the second pair, aged 2 I weeks, injected before incubation with L-methionine sulphoximine and saline respectively, the same histological differences in the gonads were observed. The third pair were 18 weeks old and had been injected on the $4^{\text {th }}$ day of incubation with L-methionine sulphoximine and DL-methionine respectively. Spermiogenesis was present in both, but sperm were much more abundant in the experimental bird. The fourth pair were only $\mathrm{r}_{4}$ weeks of age. In the experimental bird, injected on the $4^{\text {th }}$ day of 
incubation with L-methionine sulphoximine, the testicular development was that of active spermatocytogenesis, but in the control, similarly injected with $L$-methionine, the tubules were lined by a single layer of closely packed spermatogenia and Sertoli cells in which mitoses were infrequent.

\section{Effect of methionine sulphoximine on transplantable tumours in rats and mice}

Through the kindness of Professor A. Haddow, three strains of tumour, Xanthine and Walker (rat) and Crocker (mouse), together with stocks of susceptible animals, were obtained. The Jensen tumour, which it had been intended to use, was not available.

Work with the Xanthine strain proved difficult, as all the tumours that developed, both normal transplants and those in animals treated with methionine sulphoximine, were cystic. The results, as far as they went, showed no differences between the control and the test animals. Nor did intraperitoneal injections during the development of either Walker or Crocker tumours result in any differences between the methionine sulphoximine-treated animals and the controls. When, however, these two substances were added to separate parts of the same batch of tumour mush of either strain, and the mixtures were then inoculated immediately or after standing for $90 \mathrm{~min}$ at room temperature, the methionine sulphoximine resulted in some inhibition in cancer growth, either in the number or in the size of the tumours, as compared with the control substance. If the mixtures were allowed to stand for $90 \mathrm{~min}$ at $37^{\circ}$ before inoculation, methionine sulphoximine and methionine produced similar results.

The numbers of animals in each experiment were too small for definite conclusions to be drawn, and it was realized that more expert knowledge was needed to deal with the problem. Professor H. N. Green was approached and undertook to make a few tests in his laboratory in Leeds. His first experiment was on breast tumours in mice, but DL-methionine sulphoximine appeared to have no effect. He then carried out preliminary tests on rats, the results of which are shown in Table $\mathrm{I}$.

\section{Table I. Effect of methionine sulphoximine on transplantable tumours}

(All rats had transplants of $\mathrm{Rd} / 3$ sarcoma)

\begin{tabular}{|c|c|c|c|c|c|c|c|c|}
\hline \multirow[b]{2}{*}{$\begin{array}{l}\text { Exp. } \\
\text { no. }\end{array}$} & \multirow[b]{2}{*}{$\begin{array}{l}\text { Group } \\
\text { no. }\end{array}$} & \multirow{2}{*}{$\begin{array}{l}\text { No. } \\
\text { of } \\
\text { rats }\end{array}$} & \multicolumn{2}{|c|}{ DL-Methionine sulphoximine } & \multirow{2}{*}{$\begin{array}{l}\text { No. of } \\
\text { tumours } \\
\text { growing } \\
\text { to lethal } \\
\text { size }\end{array}$} & \multirow{2}{*}{$\begin{array}{l}\text { Mean } \\
\text { time of } \\
\text { death } \\
\text { (days) }\end{array}$} & \multirow{2}{*}{$\begin{array}{l}\text { Mean } \\
\text { weight of } \\
\text { tumours } \\
\text { at death } \\
\text { (g) }\end{array}$} & \multirow[b]{2}{*}{ Comments } \\
\hline & & & $\begin{array}{l}\text { Total } \\
\text { dose }\end{array}$ & Method of administration & & & & \\
\hline $\mathbf{I}$ & I & IO & $\begin{array}{l}30 \mathrm{mg} / \\
100 \mathrm{~g} \mathrm{rat}\end{array}$ & $\begin{array}{l}\text { Intraperitoneal injection: } \\
\text { ro } \mathrm{mg} / \mathrm{ro0} \mathrm{g} \text { rat at } \mathrm{I}, 5 \\
\text { and ro days following } \\
\text { transplant }\end{array}$ & 10 & 27 & 56 & $\begin{array}{l}\text { One tumour weighed } \\
\text { I04 g }\end{array}$ \\
\hline & 2 & 5 & $7 \mathrm{mg} / \mathrm{rat}$ & $\begin{array}{l}\text { Intratumoral injection: } \\
2 \mathrm{mg} \text { at } \mathrm{I} \text { day and } 5 \mathrm{mg} \\
\text { at } 16 \text { days following } \\
\text { transplant }\end{array}$ & 5 & 39 & 56 & $\begin{array}{l}\text { Very large metastases in } \\
\text { all compared with } \\
\text { other groups in both } \\
\text { experiments }\end{array}$ \\
\hline & 3 & Io & - & - & $\circ$ & - & $\cdots$ & $\begin{array}{l}\text { Eight of the ten had } \\
\text { tumours which grew } \\
\text { for a time and then } \\
\text { regressed }\end{array}$ \\
\hline 2 & I & 8 & $\begin{array}{l}20 \mathrm{mg} / \\
100 \mathrm{~g} \text { rat }\end{array}$ & $\begin{array}{l}\text { Intraperitoneal injection: } \\
\text { divided doses }\end{array}$ & 6 & 29 & 48 & - \\
\hline & 2 & 8 & - & - & 2 & 18 & $3^{8}$ & - \\
\hline
\end{tabular}


It appears that in these experiments DL-methionine sulphoximine either activated the tumour growth or broke down the natural resistance to it in the strain of rats used. It should be emphasized that the $\mathrm{Rd} / 3$ sarcoma had not, to quote Professor Green, 'adapted itself well to the rats in Leeds', so that the regression rate was unusually high, as is seen in Table I (Exp. I, group 3).

\section{SUMMARY}

I. Methionine sulphoximine retarded the growth in vitro of 89 of 103 explanted limb-bone rudiments from 6-day chick embryos.

2. When injected into the yolk sac of fertile eggs it reduced the rate of hatching by about one-half and considerably increased the mortality of young chicks.

3. Chicks from the methionine sulphoximine-treated eggs were smaller, development of their feathers was retarded, and the limb bones were shorter than in the controls.

4. In mature birds of the methionine-sulphoximine group, feathers were normal but the skeletal disproportion persisted, and in the small number of males available sexual maturity was more advanced.

5. It is of interest that in the few experiments on rats carried out by Professor Green, DL-methionine sulphoximine appeared to increase the growth of a transplantable tumour. The experiments on mice did not show this effect.

\section{REFERENCES}

Bentley, H. R., McDermott, E. E. \& Whitehead, J. K. (195I). Proc. roy. Soc. B, 138, 265.

Campbell, P. N., Work, T. S. \& Mellanby, E. (r95I). Biochem. F. 48, 106.

Fell, H. B. \& Mellanby, E. (1950). Brit. med. F. ii, 535 .

Fell, H. B. \& Mellanby, E. (1952). F. Physiol. x16, 320.

Fell, H. B. \& Mellanby, E. (1953). F. Physiol. 119, 470.

Fell, H. B. \& Mellanby, E. (1955). F. Physiol. r27, 427.

Fell, H. B. \& Robison, R. (1929). Biochem. F. 23, 767.

Mellanby, E. (1946). Brit. med. F. ii, $88_{5}$.

Toennies, G. \& Kolb, J. J. (1939). F. biol. Chem. 128, 399.

\section{EXPLANATION OF PLATES}

Plate I

1. Relative size and appearance at $3 \frac{1}{2}$ weeks of age of control chick (left) and of chick from egg injected with methionine sulphoximine.

2. Tibiae from these two birds at $8 \frac{1}{2}$ weeks of age.

3. Appearance of wing feathers I week after hatching in control (upper) and experimental bird. Poor development in the latter and contrast in feather appearance will be noted.

4. Anterior view of necks. Left, control bird; right, experimental bird. Oily appearance in the latter and difference in feather development are evident.

\section{Plate 2}

1. Birds aged 22 weeks. Upper, control bird; lower, bird from egg injected with methionine sulphoximine, showing greater development of comb and wattles and also characteristic appearance of beak.

2. Appearance of testes in a control bird (left) and in an experimental bird, 21 weeks after hatching.

3. Left, section of testis of control bird 22 weeks after hatching showing spermatocytogenesis only; right, section of testis from experimental bird of same age showing numerous spermatozoa. $\times 252$. 

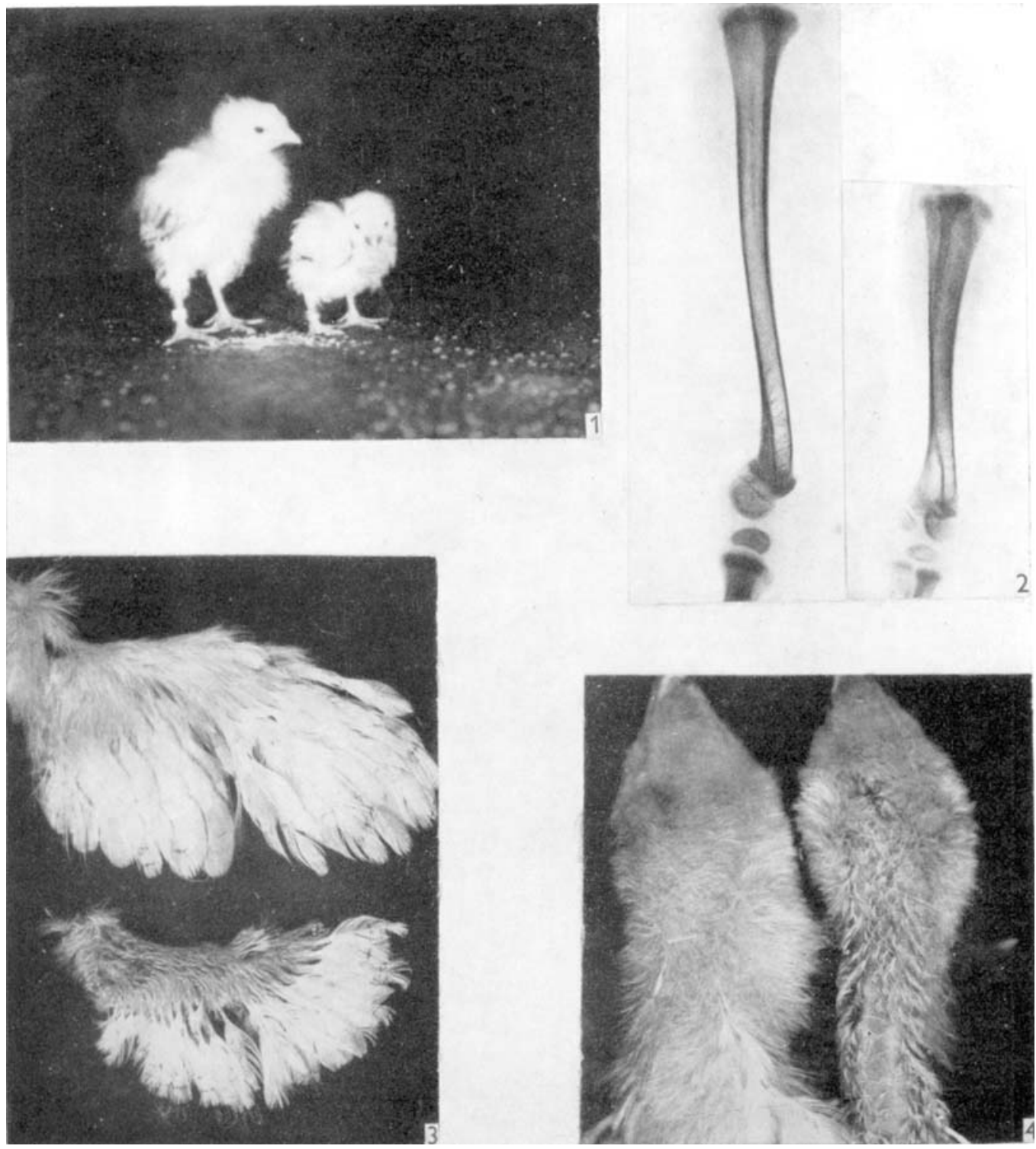

British Yournal of Nutrition, Vol. ıо, No. 3 

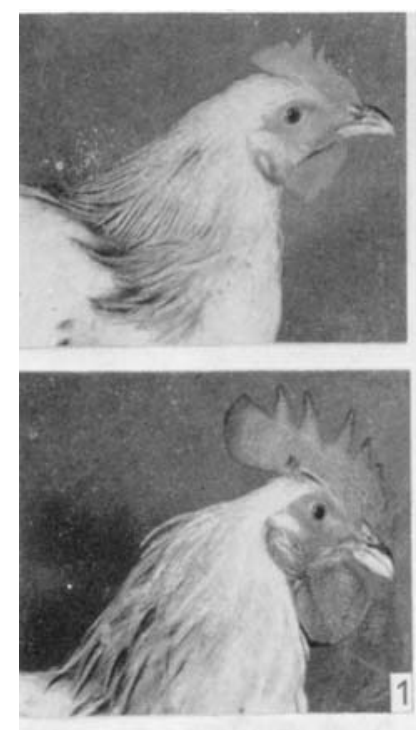
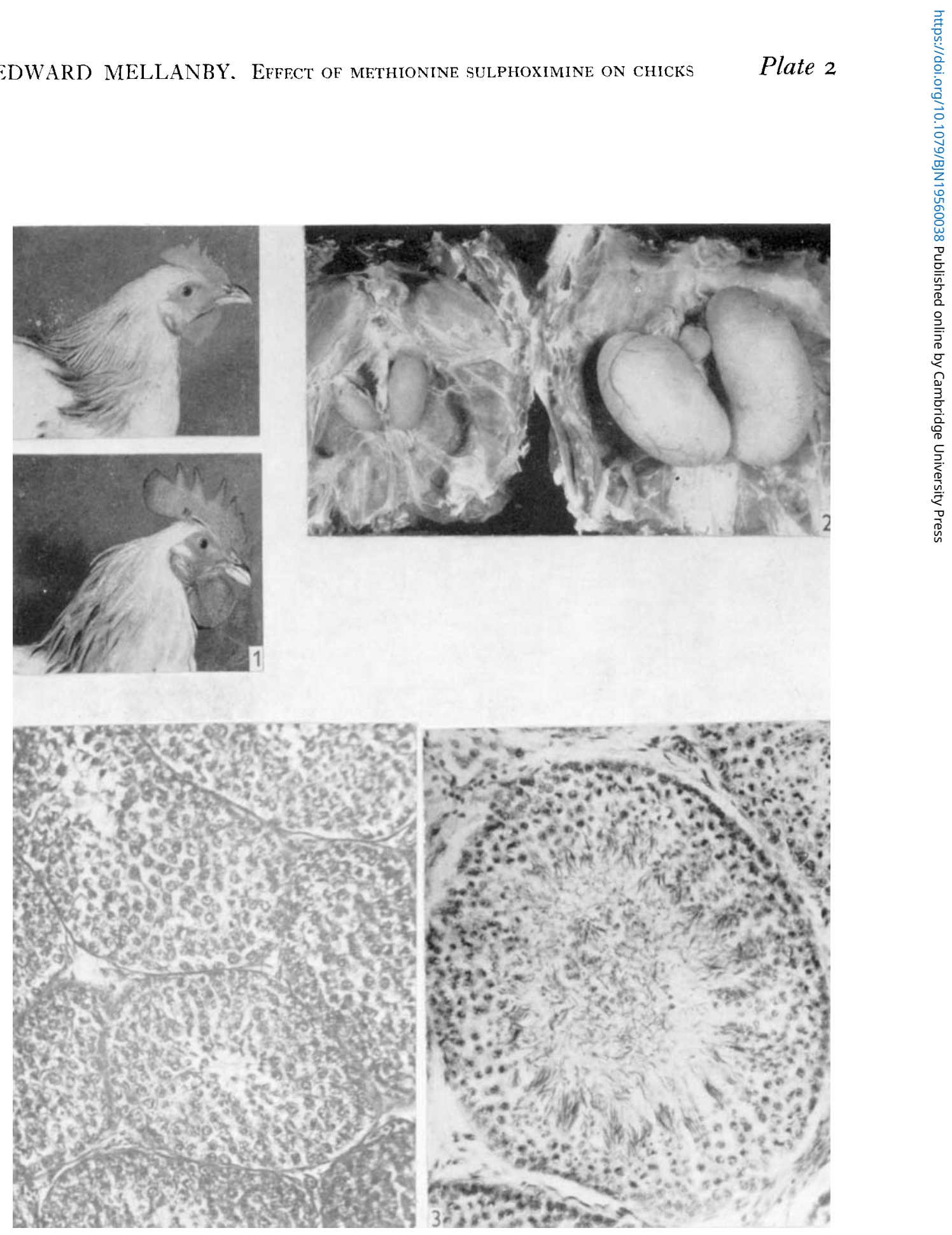

British Fournal of Nutrition, Vol. 1о, No. 3 